\title{
To Quantify Farm Women Involvement in Agriculture and Allied Activities Under Prevai Ling Cropping System and Practices in Chhattisgarh State
}

\author{
Dipti Sahu ${ }^{1}$ and Vinod Kumar Sahu \\ ${ }^{1}$ Department of Farm Machinery and Power Engineering, Vaugh School of Agricultural \\ Engineering and Technology, Sam Higginbotton Institute of Agriculture, Technology and \\ science, Allahabad (U.P.), India \\ ${ }^{2}$ Agricultural engineering, Chhattisgarh Agriculture Engineering College, Bhilai, Durg \\ (Chhattisgarh), India \\ *Corresponding author
}

\section{A B S T R A C T}

Keywords

Women's

Participation in

Agriculture works,

Work Participation

rate, Economically

Active Female

Article Info

Accepted:

05April 2020

Available Online:

10 May 2020
The entitlements of women farmers will be the key to improve agriculture productivity, It said, even as it noted that there is an increasing number of women in multiple roles in agriculture sector, as cultivators entrepreneurs and laborers. Alongside, it is focusing on women self - help groups to connect them to micro credit through capacity building activities and to provide information and ensure their representation in decision-making bodies. "Rural women are responsible for the integrated management and use to diverse natural resources to meet the daily household needs. This requires that women farmers should have enhanced access to resources like land, water, credit, technology and training which warrants critical analysis in the contest of India,"

\section{Introduction}

The advent of settled life happened with the beginning of agriculture when people started cultivating food for their livelihood. Agriculture is the vertical backbone of the country. Major part of the country's population earns its livelihood from agriculture. Our country has a wide and very old setting of agriculture of about 10 thousand years. At present in terms of agriculture production of the country holds second position across the world. The agricultural production in India encompasses field crops, fruit crops, planting crops, livestock, forestry, fishery etc. So overall it is a huge industry 
which recruits or engage $52 \%$ of overall manpower of India. The rural population of our country is mostly depending on agricultural activity.

The agriculture in country's GDP, Indian agriculture continues to remain the leading industry in the country contributing vastly in the socioeconomic growth of India. State likes Punjab, Uttar Pradesh, Madhya Pradesh, Andhra Pradesh, Haryana, Bihar, West Bengal and Chhattisgarh are the leading states in the terms of agricultural contribution of the country followed by the rest. In developing country like India, agriculture continues to absorb and employ 2/3rd of the female work force but fails to give them reorganization of employed labour. Despite of the major productive women labor force in agriculture their needs and problems are somewhat ignored by the rural development initiatives.

In rural India, the percentage of women who depend on agriculture for their livelihood is as high as $84 \%$. Women make up about $33 \%$ of cultivators and about $47 \%$ of agricultural laborers.

\section{Mean involvement of farm women}

The main focus in this study was on assessing the farm women's involvement in agriculture and allied activities. However some social factors were also included with the assumption that they are important. Information on respondents knowledge, education, occupation, landholding status, availability of milch cattle and bullocks, method of grain storage, cropping pattern, time spent by respondents in domestic, cattle rearing, agriculture and other related activities from crop production to post harvest operations, drudgery level in carrying out these operations, possession, awareness and operation of improved farm tools and equipment, food items prepared at home own consumption, physical discomfort faced by the respondents during agricultural works, training needs, awareness about extension officials and decision making pattern in family.

\section{Women's contribution in agricultural and allied activities}

Marothia and Sharma (1985) reported that, the women's contribution to the farm sector has largely been ignored and inadequately understood in the Indian context. According to the latest census, 38 per cent of all agricultural labourers, 20 per cent of cultivators and 29 per cent of all livestock and forestry workers are women. Contributing a fair share of working population, women form part of a valuable human resource that, with appropriate training and education can bring about phenomenal changes in desirable direction.

Bargali et al., (2009) has Selected farmers randomly from five villages (i.e., 20 from each village) in three blocks of Durg during of Chhattisgarh plains, a participatory rural appraisal survey conducted from 1998 to 2005. After random selection, women farmers were categorized on the basis of their landholding. 30 large (>4 ha), 41 medium (24 ha), and 29 small farm women (1-2 ha) were included in this study. After the selection of the farm women, a semi structured interview was conducted and data were recorded on their participation in different cultural practices of paddy cultivation. Some observations such as seedling transplanting, harvesting, and threshing and storage of grains and straw were also made. Minimum participation occurred in fertilizer management (2-10\%) but participation was maximum in transplanting of paddy seedlings (89-93\%). During the observations, it was noted that transplanting efficiency (number of seedlings transplanted in a unit area at one time) and harvesting efficiency (a unit area harvested by 
farm women/farmers at one time) of women workers was $26 \%$ and $14 \%$, respectively, higher than that of men workers. The maximum work participation was followed by harvesting of the crop (70-89\%), storage of grains $(70-83 \%)$, threshing $(37-42 \%)$, transportation of the harvested crop (29$38 \%)$, nursery preparation (10-20\%), irrigation of crops (10-15\%), land preparation $(10-15 \%)$, and seed selection for sowing operations $(5-15 \%)$. After that result he observed there is a need to prepare action plans for providing the skills that could enhance the working efficiency and economic conditions of rural women.

The analysis revealed significant difference between the women agricultural labourers of Kerala and Tamil Nadu with respect to their overall labour efficiency level. The difference was mainly due to labour attachment practices and increasing demand for non-agricultural works. Dimension-wise analysis of labour efficiency showed that majority of them belonged to the high group under the dimension adjustability and competency, whereas majority had low efficiency with respect to dimensions such as determination in work situation, inter-personal relationship, team spirit, commitment, work environment, socio-economic and situational. The respondents were observed to have neither high nor low efficiency in case of confidence dimension.

\section{Materials and Methods}

Chhattisgarh state has been divided into three Agro-climatic zone viz. Chhattisgarh plains, Bastar Plateau and Northern Hill zone, covering $51.0 \%, 28.0 \%$ and $21.0 \%$ of the geographical area, respectively. The district from the Chhattisgarh plains was selected. Out of which two blocks namely Gunderdehi and Gurur block has been identified for the purpose of study. Two villages from each block were selected for conduction of data collection work. In this study 30 farmers including women from each of the village (total four) were interviewed personally for recording all necessary observation as per proforma developed.

\section{Location of the Study Area}

The District Head Quarter of Durg Balod is in Durg, which is situated on National Highway 200. Durg is $35 \mathrm{~km}$ from State capital Raipur through road route. District head quarter Durg is also connected with Rail Line of SouthEastern-Central Railway. It is situated on Howrah-Mumbai main line. State capital Raipur is $40 \mathrm{~km}$ from Durg through Rail route. The railway station of district Durg and Bhilai Nager.

On the basis of area Durg Balod district is the third smallest district of Chhattisgarh State having an area of $4015 \mathrm{~km}^{2}$. It is situated north of Mahanadi and is surrounded by Raipur, Rajnandgaon, Kanker \& Dhamtari districts. The total population of the district as per census 2011 is 1316140 , having the highest population density of 342 within the State. The district is administratively divided into 8 development Blocks and having total 913 villages and 6 Townships.

The Gangrel project has been considered as life supporting canal for the district Durg Balod. The Normal rainfall is $1478 \mathrm{~mm}$ in the district. Total $889 \mathrm{~km}^{2}$ area of the district is covered by forest. Agriculture is the main occupation of the district. Net sown area is $2645.59 \mathrm{~km}^{2}$ (on 2000 data) with only 672.02 $\mathrm{km}^{2}$ is double cropped area. Principal crop is rice sown in $2605.62 \mathrm{~km}^{2}$ areas i.e. $98.34 \%$ of total sown area. $99.66 \%$ villages where provided with drinking water source. Almost $90 \%$ of drinking water supply is from Ground Water in the district. Total hand pumps are 5776 where as power pumps are 3153 tapping ground water in the district. 84 water supply schemes are running tapping ground water in the district. 


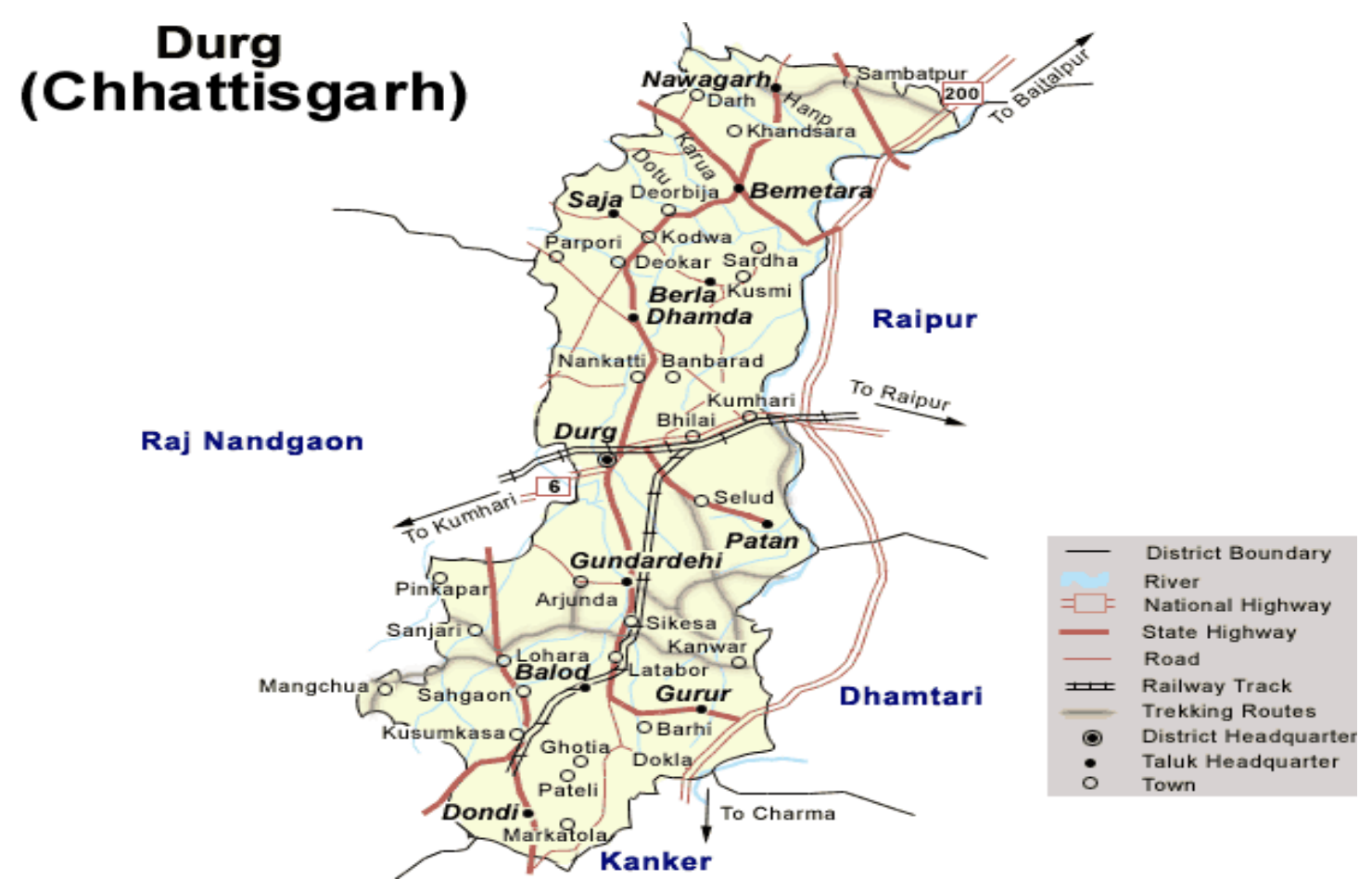

Fig.1 Map of Durg Balod district

\section{Developing the Interview Schedule}

To collect information leading to fulfill the objectives of this study each farmer was interviewed separately. In order to obtain the complete information on each operation/activity a detailed schedule (proforma) was developed by incorporating the suggestions given by AICRP on UAE and NRCWA, Bhopal. Prior to data collection. Questions pertaining to farmers detail, agril. operations, implements being used by farmers and their details, implements/power source available, animal power utilization, women contributions and specification of implements were asked and recorded.

\section{Method of Data Collection:}

The data were collected through personal interview of the farmers and farmwomen on the pre - tested proforma (Appendix - A) by using recall method for all the selected farmers falling in different categories. The information about household activities was collected through interview of the counterparts of the farmers. Actual observations of some activities were also recorded during the field operations in a few villages. The time and labour required for various farm operations mainly field preparation, sowing, transplanting, irrigation, manuring, fertilizer application, weeding, plant protection, harvesting, threshing, drying and transportation were recorded for each crop under study on the basis of the verbal interview of the farmers. Thus the data in terms of time and labour required to accomplish different field operations and household activities along with other basic information were collected individually from all the selected farmers.

\section{Data Processing}

Adopting standard techniques suggested by the research workers the data thus collected was processed. First of all the data for animal power utilization was arranged separately for different categories of respondents for each 
village. The values thus found were arranged in tabular form separately for each category of farmers.

\section{Involvement of farm women in a operation}

It indicates the per cent of the respondents involvements in the particular operation. If the involvement of farm women in intercultural operation was $89.96 \%$ means out of 100 respondents 89 respondent were involved in this operation.

\section{Mean involvement of farm women}

It is the average of ten farm operations. Based on respondents involvement in ten operations, their mean involvement was calculated to show their overall involvement in agriculture.

\section{Sampling Procedure}

The main focus of study was on the animal power utilization, tractor power utilization and farm women and their involvement in agriculture and allied activities in the state. Therefore, only the draught animal, farm women and male farmers were considered separately for the study. To identify the location of survey sites in the selected district of the zone villages were grouped block wise. The farmers were selected randomly. After that population of the farmers were grouped under different categories for all the four villages. The categories viz. marginal (<1ha), small (1-2ha), semi-medium (2-4ha), medium (4-6ha) and large (>6ha) of farmers, selected in each of the village.

\section{Selection and Measurement of Variables}

The main focus in this study was on assessing the farm women's involvement in agriculture and allied activities. However some social factors were also included with the assumption that they are important.
Information on respondents knowledge, education, occupation, landholding status, availability of milch cattle and bullocks, method of grain storage, cropping pattern, time spent by respondents in domestic, cattle rearing, agriculture and other related activities from crop production to post harvest operations, drudgery level in carrying out these operations, possession, awareness and operation of improved farm tools and equipment, food items prepared at home own consumption, physical discomfort faced by the respondents during agricultural works, training needs, awareness about extension officials and decision making pattern in family.

\section{Results and Discussion}

This chapter briefly presents the findings of the survey conducted in Durg, Balod district of Chhattisgarh Plains region. To find out the animal power utilization and women's power contribution in agriculture and allied activity under existing farm practices, a detailed survey of farm families comprising of different land holding sizes was conducted. Survey revealed that the respondents belong to different castes, and have education level from illiterate to college level. Many farmers, especially those who have their own irrigation sources, take summer paddy also.

\section{Villages under study and infrastructure facility}

The summary of information collected about the sample Blocks and villages are presented in Graph 1 and Graph 2. Two villages from each block were selected for survey work. It is observed that all the four villages are more or less of the same category on the basis of no. of farm families. All the villages were 15 to $17 \mathrm{~km}$ away to each other and these villages are connected by concrete muroom roads. In all the villages He-buffaloes is popular as a source of draught power. Total 
30 respondents from each of the village were selected for personal interview to record the observations.

\section{General and social attributes}

The population density of Chhattisgarh state is 154 and in the district it is 342 persons per $\mathrm{km}^{2}$. The sex ratio of state and district is very similar to each other ranges between 989 and 999 female per thousand males. The main dialect of the district is Chhattisgari. District has mainly backward class population and tribes like Satnami, Gond, Kanwar etc, are found in the district. District is well connected with the rest of the state through road and the two tehsils namely, Gunderdehi and Dondi are connected with railways. $98.15 \%$ villages of the district are electrified. There are eight blocks in the district (Dondi, gunderdehi, Gurur, Nawagarh, Bemetara, Patan, Saja and Dondi Lohara) out of them two blocks (Nawagarh, gurur and Gunderdehi) have only rural population and also urban both. In four blocks (Dhamdha, Bemetara, Nawagarh and gunderdehi) female population is more than males. About $22 \%$ and $13 \%$ population of the district are Schedule Caste (SC) and Schedule Tribes (ST), respectively. The percentage of ST population is highest $(27.14 \%)$ in Dondi, Gurur and Bemetara Block and lowest (6.23\%) in Patan, Saja and Nawagarh Block (Table - 1). There are six Block Resource Centers (BRCs), one each in all the blocks. As per 2011 census the male, female and total literacy is $82.21 \%, 50.41 \%$ and $66.26 \%$, respectively.

Graph.1 Category wise population in different blocks

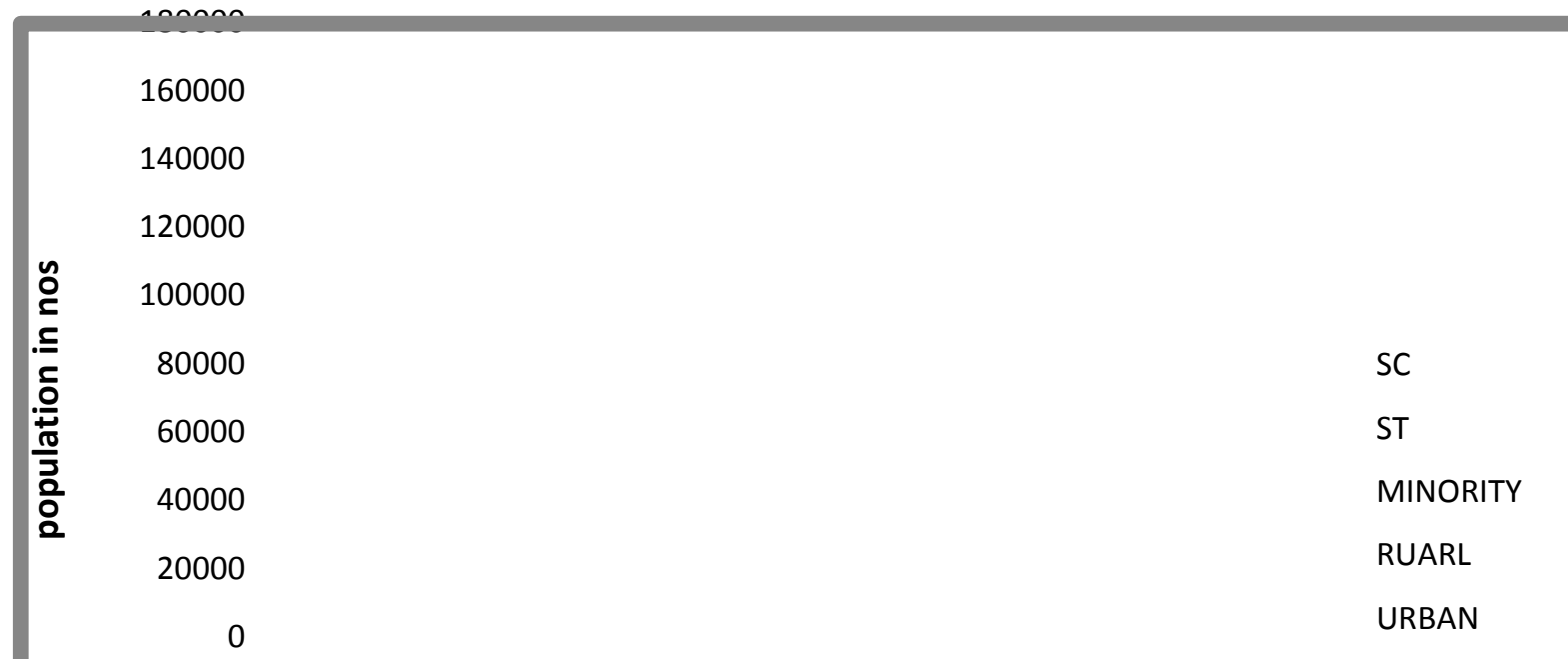

name of blocks 
Graph.2 Sex wise population in different blocks
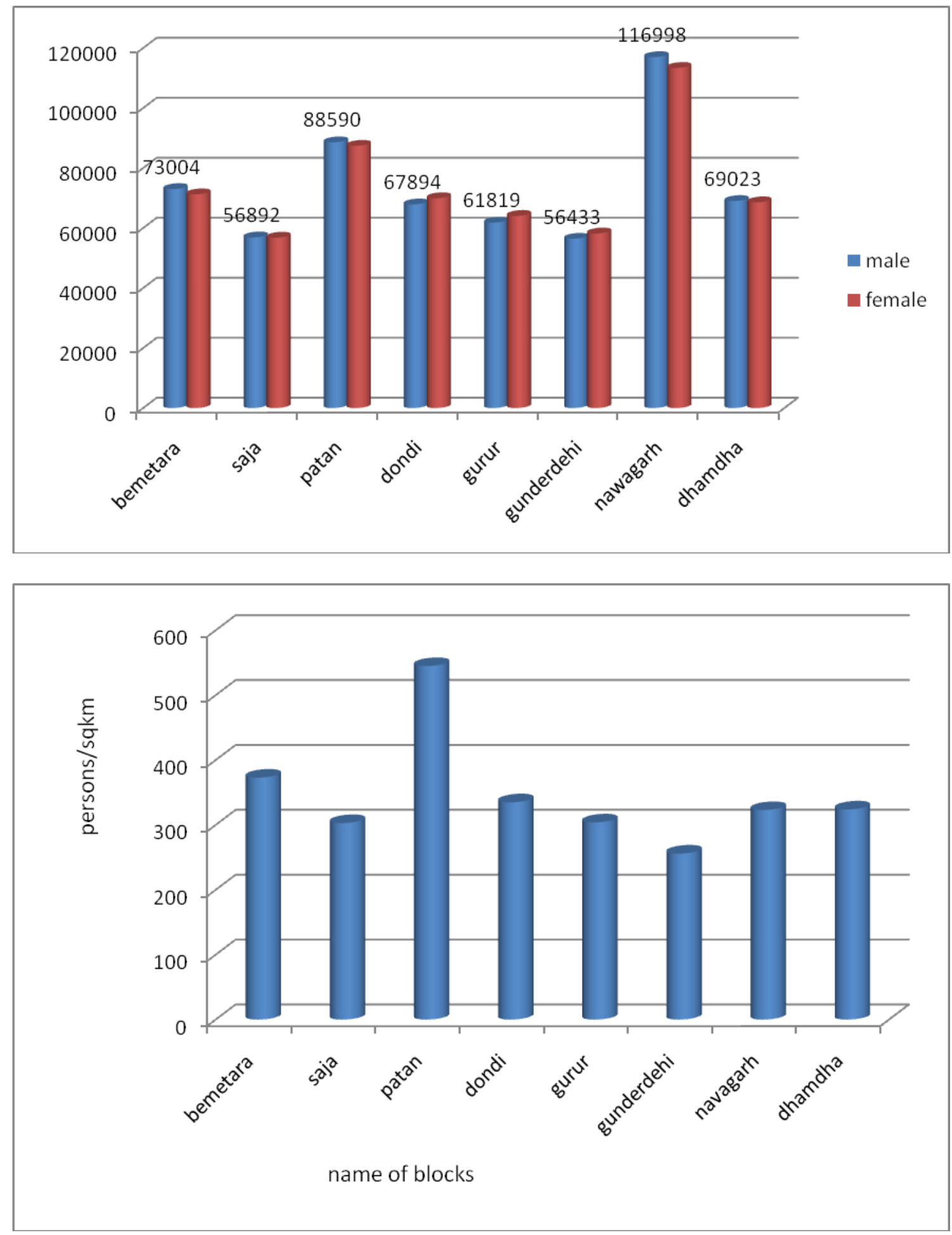

In conclusion, the purpose of this study is to analyze the women participation in agriculture across diverse Indian state based on secondary data score. Efforts were made to systematically collate the data and analyze the trend of women participation in each state. In 
a Chhattisgarh the survey said a genderspecific intervention to raise productivity of small farm holdings is required, as is engagement of men and women in extension services. In Chhattisgarh state the entire work can be concluded with the facts that women participation in agriculture is increasing with time and women are now acknowledgement with the status of agricultural workers and participation in agriculture. Though discrimination of wages and in working status still prevails for women labour but due to implementation of various policies and initiatives taken by government the invisibility of women as an agricultural workers is plummeting and will further diminish in future.

\section{References}

Aggarwal, M. 2003. Economic Participation of Rural Women in Agriculture. Economic Empowerment of Rural Women in India, Edited by Gopal Singh 2003, RBSA Publications Jaipur, Rajasthan.

Anonymous. 1995. Utilization of animal energy through effective animal machine system in Baster region. Final report of ICAR ahhoc project pp 1-69. Anonymous. 2001. Empowerment of Women in Agriculture, Policy Paper11; National Academy of Agricultural Science, India, September 2001.

Anonymous. 2005. The Kamdhenu bullocks drawn tractor. Bhartiya Cattle Resource Development Foundation. Rajasthan. Website www.cowindia.org Bargali, S.S., Pandey, K., Singh, L. and Shrivastava, S.K. 2009. Participation of rural women in rice-based agroecosystems. IGKV, Raipur.

Chandurkar, P.S. 2001. Training and education on IPM. IPM Mitr. 11:91-97.

Chaudhary, H. and Singh, S., 2003. Farm Women in Agriculture Operations. Agricultural Extension Review. 15(1): 21-23.

Chaudhury, Sarmishtha. 2004. Invisible Activities of Rural Women. Kurukshetra, Vol. 52, No. 9, July 2004.

Dave, A.K. 1999. Animal drawn tillage system for rice cultivation under rainfed condition. Agricultural Mechanization in Asia, Africa and Latin America, 30(3): 28-30.

\section{How to cite this article:}

Dipti Sahu and Vinod Kumar Sahu. 2020. To Quantify Farm Women Involvement in Agriculture and Allied Activities Under Prevai Ling Cropping System and Practices in Chhattisgarh State. Int.J.Curr.Microbiol.App.Sci. 9(05): 700-707.

doi: https://doi.org/10.20546/ijcmas.2020.905.078 